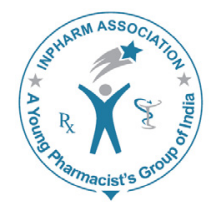

\title{
Evaluation of anti-arthritic activity of Caesalpinia pulcherrima in freund's complete adjuvant induced arthritic rat model
}

\author{
Cuddapah Rajaram¹, Kandula Ravindra Reddy ${ }^{2}$, Kothapalli Bonnth Chandra \\ Sekhar ${ }^{3}$ \\ ${ }^{1}$ Department of Pharmacology, P. Rami Reddy Memorial College of Pharmacy, Kadapa-516003, AP, India. \\ ${ }^{2}$ Department of Pharmaceutics, CES College of Pharmacy Kurnool-518 218, AP, India.
}

${ }^{3}$ Department of Chemistry, Jawaharlal Nehru Technological University Ananthapur, Ananthapuramu -515

002, AP, India.

\section{ABSTRACT}

Objective: To investigate the anti-arthritic activity of ethanolic extract of Caesalpinia pulcherrima (ECP) in adjuvant arthritic (AA) rat model induced by Freund's complete adjuvant (FCA). Methods: Thirty healthy albino rats were selected and randomly divided into five groups. Arthritis was induced by Freund's complete adjuvant (FCA) and then treated with ethanolic extract of Caesalpinia pulcherrima for 28 days. The various parameters like paw volume, haematological parameters (RBC, WBC, Hb and ESR), and radiological studies were assessed. Results: In FCA induced arthritic rats, there was significant increase in rat paw volume whereas both doses of ECP treated groups showed strong significant reduction in paw volume. The altered haematological parameters in the arthritic rats were significantly recovered to near normal by the treatment with ECP at the dose of 200 and $400 \mathrm{mg} / \mathrm{kg}$. Further radiological studies revealed the anti-arthritic activity of ECP by preventing cartilage and bone destruction of the arthritic joints of AA rats. Conclusion: ECP has shown anti-arthritic activity with a significant decrease in paw volume and it could significantly normalize the haematological abnormalities in adjuvant induced arthritic rats. Further radiological studies confirmed the anti-arthritic activity of ECP.

Key words: Arthritis, Caesalpinia pulcherrima, Freund's complete adjuvant, Haematological, Paw volume.

\begin{tabular}{|c|c|}
\hline \multicolumn{2}{|c|}{ Access this article online } \\
\hline Journal Sponsor & \multirow[b]{2}{*}{$\begin{array}{l}\text { Website: } \\
\text { www.jyoungpharm.org }\end{array}$} \\
\hline \multirow{2}{*}{ www.phcog net } & \\
\hline & DOI: 10.5530/jyp.2015.2.12 \\
\hline
\end{tabular}

\section{INTRODUCTION}

Rheumatoid arthritis (RA) is a chronic, systemic autoimmune disorder that is associated with symmetrical, inflammatory polyarthritis that may produce progressive joint damage. Inflammation of the joint tissues is associated with

\footnotetext{
*Address for correspondence:

Dr. Cuddapah Rajaram, Department of Pharmacology, P. Rami Reddy Memorial College of Pharmacy, Kadapa-516003, AP, India.

E-mail: rajaram212121@gmail.com
} 
the release of toxic substances in the synovium that leads to cartilage destruction. ${ }^{1}$ NSAIDS, Disease-Modifying Anti-Rheumatic Drugs (DMARDS), Biologic Response Modifiers and Corticosteroids are the most commonly used drugs for the treatment of RA. However, all of these agents are associated with numerous side effects. In present days, investigators are conducted towards traditional system of medicine for the exploration of drugs that are long acting anti-inflammatory with minimal side effects. The arthritis-like symptoms in AA rats share several histopathological features with human RA, including mononuclear cell infiltration and synoviocyte hyperplasia that results in pannus formation followed by bone and cartilage destruction. ${ }^{2}$ The similarities in the joint pathology between rat arthritis and human RA are most widely used for studying the pathogenesis of human RA and for searching new drugs for RA management. Therefore, AA is most frequently used as a model for screening and testing anti-arthritic agents. ${ }^{3}$

Caesalpinia pulcherrima is a medicinal plant belonging to the family Caesalpiniaceae. It is an ornamental plant due to its variety of flowers, which appear yellow, pink, off-white, and red with yellow margins. ${ }^{4}$ Phytochemical studies made known the presence of pulcherrimin, terpenoids, sitosterol, flavonoids like quercetin and myricetin, carotenoids, glycosides, steroids, and phenols. ${ }^{5}$ It is popular in Indian indigenous system of medicine like Siddha, Unani, Homoeopathy and Ayurveda. In traditional system of medicine, this plant has been used for anti-inflammatory, bronchitis, abortifacient, and malarial infection. ${ }^{6}$ Although the plant possesses many potential therapeutic activities in traditional system and containing rich phytochemical constituents, no work has been still done about the antiarthritic activity. Taking these facts into considerations, the present study made an attempt to evaluate the antiarthritic activity of ethonolic extract of $C$. pulcherrima against freund's complete adjuvant induced arthritis in experimental rats.

\section{MATERIALS AND METHODS}

\section{Plant material}

The whole plant was collected from local area of kadapa, India. The plant product was authentified by Dr. K. Madava chetty, botanist, Department of Botany, SV University, Tirupathi, India. A voucher specimen (no.SV-30472) was deposited in the Department of Pharmacology, PRRM College of Pharmacy, Kadapa, India. The whole plant was shade dried and reduced mechanically to moderate coarse powder and stored in air tight vessel for further use.

\section{Preparation of the extract}

Extraction was done according to standard procedure using analytical grade solvents. The coarse powder of the whole plant $(1 \mathrm{~kg})$ was soxhlet extracted with $90 \%$ ethanol. The extract obtained was concentrated under vacuum to turnout ethanolic extract $(18.70 \%)$.

\section{Experimental animals}

Healthy adult male albino rats of Wistar strain 150-200 g were used. The experimental procedures and protocols were approved by the Institutional Animal Ethical Committee and allocate the NO: 1423/PO/a/11/CPCSEA/02/2013. Animals were housed under standard conditions of temperature $\left[24^{\circ} \mathrm{C}\right]$ and relative humidity $(30 \%-70 \%)$ with a 12:12 light: dark cycle. Animal handling was performed according to Good Laboratory Practice. The animals were given standard diet and water ad libitum.

\section{Acute toxicity studies}

Acute oral toxicity study of ethanolic extract of C.pulcherrima was performed in line with OECD guidelines 423.

\section{Induction of arthritis}

On day 0 rats were injected with $0.1 \mathrm{ml}$ of FCA in to the sub plantar (s.p) region of the left hind paw of all the animals. This consists of Mycobacterium butyricum suspended in heavy paraffin oil by thoroughly grinding with a pestle and motor to give a final concentrate of $0.6 \mathrm{mg} / \mathrm{mL}$. Administration of test compounds and standard drug was started on the next day and continued for 28 days.

\section{Experimental set up}

Total animals were randomly divided into five groups, each group containing 6 animals and treated for 28 days. The standard drug ibuprofen and ECP were suspended in 1\% CMC with glass mortar, made as a suspension and administered immediately. Group I -Normal rats received distilled water; Group II- Arthritic rats administered CMC; Group III- Arthritic rats received ibuprofen $15 \mathrm{mg} / \mathrm{kg}$, p.o. suspended in CMC; Group IV- Arthritic rats treated with ECP at dose of $200 \mathrm{mg} / \mathrm{kg}$, p.o; Group V- Arthritic rats treated with ECP at dose of $400 \mathrm{mg} / \mathrm{kg}$, p.o. The paw was marked with ink at the level of the malleolus laterials and paw volumes were recorded by the plethysmometer 
Table 1: Effect of ECP on FCA induced Paw volume

Groups

Group I

Group II

Group III

Group IV

Group V

$20 \pm 0.04$

$0.25 \pm 0.02$

$0.35 \pm 0.05$

$0.40 \pm 0.04$

$0.35 \pm 0.02$

$0.52 \pm 0.02^{* *}$

Paw volume $(\mathrm{mL})($ mean \pm SEM)

Day

$0.20 \pm 0.06$

$0.67 \pm 0.02^{\# \# \#}$

$0.67 \pm 0.02$

$0.20+0.05$

Day 21

$0.20 \pm 0.05$

$0.94 \pm 0.02^{\# \# \#}$

$0.92 \pm 0.04^{\# \# \#}$

$0.62 \pm 0.04^{\star \star}$

$0.57 \pm 0.06^{\star \star *}$

$0.72 \pm 0.02^{*}$

$0.72 \pm 0.06^{*}$

$0.62 \pm 0.04^{* *}$

$0.60 \pm 0.04^{\star * *}$

s. $p=$ subplantar; \#\#\# indicate $p<0.001$ when compared to normal group. ${ }^{*} P<0.05,{ }^{\star \star} P<0.01,{ }^{* \star *} P<0.001$ when compared to control group.

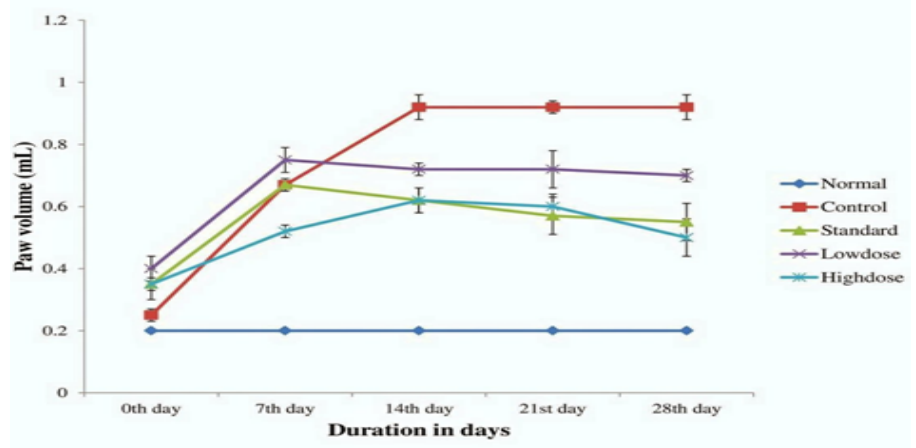

Figure 1: Effect of ECP on paw volume in arthritic rats

immediately after injection and on $7^{\text {th }}, 14^{\text {th }}, 21^{\text {st }}$ and $28^{\text {th }}$ day. $^{7}$

\section{Haematological screening}

White blood cell (WBC) and Red blood cell (RBC) counts were assessed as stated in the method of Chesbrough and McArthur. ${ }^{8}$ Drabkin and Austin method was used to confirming the Hemoglobin (Hb) content. ${ }^{9}$ Estimation of erythrocyte sedimentation rate (ESR) was carried out by the method of Westergren. ${ }^{10}$

\section{Radiographic analysis}

X-ray images were taken for the affected paws of experimental rats, and checked for the soft swelling, bony erosions and narrowing of the spaces between joints. ${ }^{7}$

\section{Data analysis}

Results were analyzed using one way analysis of variance (ANOVA) followed by the tukey's test by using statistical software package, Graph Pad Prism; version 5.03. Values were expressed as mean \pm SEM and the $\mathrm{p}<0.05$ were considered as statistically significant.

\section{RESULTS}

\section{Acute toxicity study}

There was neither change in behavioral pattern or any sign of toxicity during the observations up to $24 \mathrm{~h}$ for mortality. The extracts were safe up to a maximum dose of $4000 \mathrm{mg} /$ $\mathrm{kg}$. The biological evaluation was carried out at doses of 200 and $400 \mathrm{mg} / \mathrm{kg}$.

\section{Anti-arthritic activity}

\section{Effect of ECP on paw volume}

Rats injected with FCA (group II) showed a significant increase in paw volume when compared to the normal rats (group I). Ethanolic extract treatment at the dose of $200 \mathrm{mg} / \mathrm{kg}$ and $400 \mathrm{mg} / \mathrm{kg}$ showed significant reduction in rat paw volume when compared with the group-II rats (Table 1 and Figure 1).

\section{Effect of ECP on Haematological parameters}

A significant reduce in the levels of $\mathrm{Hb}$ and $\mathrm{RBC}$ was observed in control rats (group II) when compared to normal rats (group I). Administration of ECP to diseased rats (group IV and group V) enhanced the levels of RBC and $\mathrm{Hb}$ to close normal levels. The raise in WBC count

Journal of Young Pharmacists Vol 7 • Issue 2 • Apr-Jun 2015 


\begin{tabular}{|c|c|c|c|c|}
\hline Groups & RBC (millions/cmm) & WBC (thousands/cmm) & $\mathrm{Hb}(\mathrm{gm} / \mathrm{dL})$ & $\operatorname{ESR}(\mathrm{mm} / \mathrm{hr})$ \\
\hline Group I & $7.25 \pm 0.55$ & $9.80 \pm 0.14$ & $13.00 \pm .25$ & $1.25 \pm 0.25$ \\
\hline Group II & $3.46 \pm 0.22^{\# \# \#}$ & $21 \pm 1.37^{\# \# \#}$ & $9.075 \pm 0.22^{\# \# \#}$ & $47.00 \pm 7.50^{\# \# \#}$ \\
\hline Group III & $5.05 \pm 0.42^{* * *}$ & $15.40 \pm 0.33^{* * *}$ & $12.15 \pm 0.09^{* * *}$ & $2.75 \pm 0.47^{* * *}$ \\
\hline Group IV & $7.23 \pm 0.32$ & $16.25 \pm 0.39^{* * *}$ & $11.27 \pm 0.63^{* *}$ & $9.75 \pm 1.31^{* *}$ \\
\hline Group V & $7.77 \pm 0.56^{* *}$ & $11.91 \pm 0.88^{* * *}$ & $11.45 \pm 0.26^{* * *}$ & $9.82 \pm 0.42^{* * *}$ \\
\hline
\end{tabular}

s. $p=$ subplantar; \#\#\# indicate $p<0.001$ when compared to normal group. ${ }^{*} \mathrm{P}<0.05,{ }^{\text {**}} \mathrm{P}<0.01,{ }^{* *} \mathrm{P}<0.001$ when compared to control group.

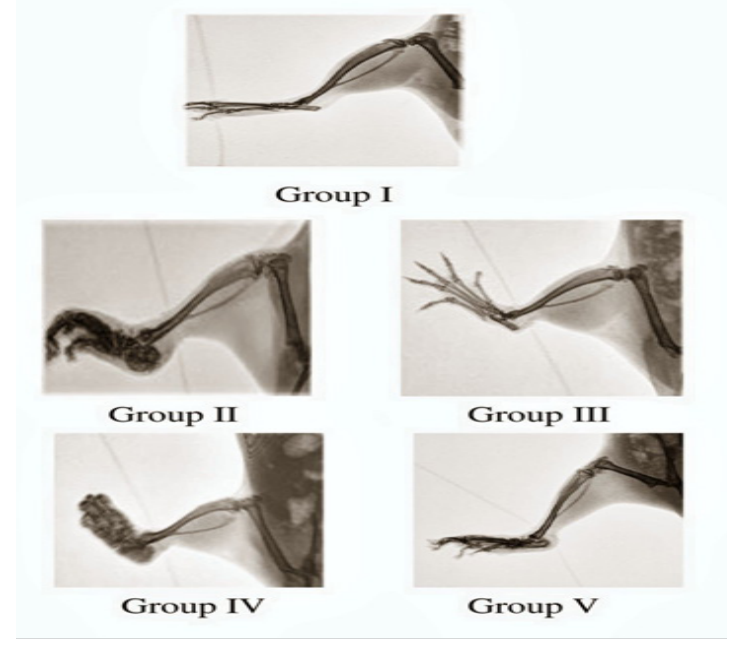

Figure 2: Radiology of affected paw in arthritic rats

and ESR were significantly overcome in the extract treated groups (group IV and group V) (Table 2).

\section{Radiographic analysis}

The results were observed from $\mathrm{X}$ - ray was the normal group animals showed absence of soft tissue swelling and bony destruction. The arthritis control group animals was found with soft tissue swelling along with narrowing of joint spaces and sign of bony destruction. The treatment groups have shown prevention against bony destruction and narrowing of joint spaces by showing less soft tissue, swelling (Figure 2).

\section{DISCUSSION}

Rheumatoid Arthritis is a common autoimmune disorder, the immunologically mediated FCA induced arthritic model is considered as one of the outstanding animal model of RA. FCA induced arthritis is an animal model of chronic polyarthritis with features that look like RA. ${ }^{11}$ Determination of paw oedema is according to the grapevine simple, susceptible and rapid procedure for evaluate the degree of inflammation and assess the therapeutic effects of drugs. ${ }^{12}$
In adjuvant-induced arthritic rats developed a chronic swelling in multiple joints with influence of inflammatory cells, erosion of joint cartilage and bone destruction and remodelling which have close similarity to human RA. These inflammatory changes eventually result in the complete destruction of joint stability and mobility in the arthritic rats. Also, soft tissue swelling around the ankle joints was appeared during the progress of arthritis in FCA injected rats, which was considered as oedema of the exacting tissues. ${ }^{13}$

C. pulcherrima at doses of 200 and $400 \mathrm{mg} / \mathrm{kg}$ significantly and dose dependently inhibited paw swelling in arthritic rats. The cardinal signs of the chronic inflammatory reactions like swelling, redness, arthalgia and inactivity of affected joints were significantly less in the drug treated animal than those of the control rats.

In present study, arthritic control rats showed a reduced $\mathrm{RBC}$ count, reduced $\mathrm{Hb}$ levels, and an increased erythrocyte sedimentation rate (ESR). All these symptoms indicate an anemic condition. ${ }^{14}$ The $C$. pulcherrima treated groups showed a significant recovery from the induced anemia. The significant increase in leukocyte count in adjuvantinduced arthritic rats may be due to the stimulation of immune system against the invading antigens and significant decrease in C. pulcherrima treated groups showed 
its immunomodulation effect. This clearly indicates the anti-arthritic activity of $C$. pulcherrima.

Radiographic changes in RA conditions are useful indicative measures which specify the severity of the disease. Soft tissue swelling is the earlier radiographic sign, whereas important radiographic changes like bony erosions and narrowing of joint spaces can be observed only in the developed stages of arthritis. ${ }^{15}$ The radiographic features of the rat joints in adjuvant induced arthritic model are shown in Figure 2. In adjuvant induced arthritic rat (group II), soft tissue swelling along with narrowing of the joint spaces were observed which implies the bony destruction in arthritic condition. The group receiving ECP at dose $400 \mathrm{mg} / \mathrm{kg}$ has shown significant prevention against bony destruction by showing less soft tissue swelling and narrowing of joint spaces when compared to arthritic control group.

Phytochemical investigations on C.pulcherrima have shown the presence pulcherrimin, terpenoids, sitosterol, lupeol, flavonoids like quercetin and myricetin, carotenoids, glycosides like sophorin, phenols, and steroids. ${ }^{5}$ These components may exert its anti-inflammatory activity by inhibiting the 5-lipoxygenase pathway, which together with the COX-2 pathway, is very important in producing and maintaining inflammation. This previously has been shown

\section{REFERENCES}

1. Darlington LG, Ramsey NW. Review of dietary therapy for rheumatoid arthritis. Br J Rheumatol. 1993; 32(6): 507-14.

2. Bendele A, McComb J, Gould T, McAbee T, Sennello G, Chlipala $\mathrm{E}$, et al. Animal models of arthritis: relevance to human disease. Toxicol Pathol. 1999; 27(1): 134-42.

3. Billingham ME. Models of arthritis and the search for antiarthritic drugs. Pharmacol Ther. 1983; 21(3): 389-428.

4. Roach JS, McLean S, Reynolds WF, Tinto WF. Cassane diterpenoids of Caesalpinia pulcherrima. J. Nat. Prod. 2003; 66(10): 1378-1381.

5. Sharma V, Rajani GP. Evaluation of Caesalpinia pulcherrima Linn. for anti-inflammatory and antiulcer activities. Indian J Pharmacol. 2011; 43(2): 168-171.

6. Srinivas KVNS, Koteswara Rao Y, Mahender I, Das B, Krishna KVSR, Kishore KH, et al. Flavonoids from Caesalpinia pulcherrima. Phytochemistry 2003; 63(2): 789-93.

7. Petchi RR, Vijaya C, Parasuraman S. Anti-arthritic activity of ethanolic extract of Tridax procumbens (Linn.) in Sprague Dawley rats. Phcog Res 2013;5(2):113-7.

8. Chesbrough M, McArthur J. Laboratory Manual of Rural Tropical to possess anti-inflammatory property of C. pulcherrima. $^{5}$ The presence of these compounds in the $C$. pulcherrima extract may explain the anti-arthritic properties of this plant. Taken together, our results strongly support the anti-arthritic potential of the plant $C$. pulcherrima and its use in traditional medicine.

\section{CONCLUSION}

The results obtained in this present study indicates that $C$. pulcherrima not only directs towards the control of arthritis progression and/or the inflammation associated with joint synovitis, but also prevents cartilage and bone destruction of the arthritic joints of AA rats. Hence, orally applicable $C$. pulcherrima, may have great potential as an alternative to the therapeutic agents currently available for treatment of RA.

\section{CONFLICT OF INTEREST}

We declare that we have no conflict of interest.

\section{ACKNOWLEDGEMENT}

Thanks to management of P. Ramireddy Memorial College of Pharmacy for providing all the necessary stuff required for this study and also their moral support.

Hospitals. The English Language Book Society and Churchill Livingstone: London; 1972.

9. Austin JH, Drabkin DL. Estimation of Haemoglobin. J. Biol. Chem. 1935; $112: 67-9$.

10. David G, Sykes AJ. Westergren and Wintrobe methods of estimating ESR compared. Br Med J. 1951; 2(4746): 1496-7.

11. Pathak N, Gohil P, Patel NB, Kasture S, Jivani N, Bhalodia Y. Curative Effect of Albizia lebbeck methanolic extract against adjuvant arthritis-With special reference to bone erosion. Int $\mathrm{J}$ Pharm Sci Drug Res. 2009; 1(1):183-7.

12. Singh S, Majumdar DK. Effect of fixed oil of Ocimum sanctum against experimentally induced arthritis and joint edema in laboratory animals. Int J Pharmacog.1996; 34(3): 218-22.

13. Yend SR, Sannapuri VD, Vyawahare NS, Harle UN. Antirheumatoid activity of aqueous extract of Piper nigrum on Freund's Adjuvantinduced arthritis in rats. Int J Pharma Sci Res. 2010; 1(1): 129-33.

14. Mowat AG.Hematologic abnormalities in Rheumatoid arthritis. Sem. Arthr. Rheum 1971; 1(3): 195-219.

15. Harris ED. Rheumatoid arthritis. Pathophysiology and implications for therapy. N Eng J Med. 1990; 322(18): 1277-89. 